\title{
Comparison of the Spatiotemporal Variability of Temperature, Precipitation, and Maximum Daily Spring Flows in Two Watersheds in Quebec Characterized by Different Land Use
}

\author{
Ali A. Assani, Raphaëlle Landry, Christophe Kinnard, Ouassila Azouaoui, \\ Christine Demers, and Karine Lacasse \\ Department of Environmental Sciences, University of Quebec at Trois-Rivieres, 3351 Boulevard of the Forges, \\ Trois-Rivières, QC, Canada G9A $5 H 7$ \\ Correspondence should be addressed to Ali A. Assani; ali.assani@uqtr.ca
}

Received 26 February 2015; Revised 26 June 2015; Accepted 30 June 2015

Academic Editor: Fubao Sun

Copyright (C) 2016 Ali A. Assani et al. This is an open access article distributed under the Creative Commons Attribution License, which permits unrestricted use, distribution, and reproduction in any medium, provided the original work is properly cited.

We compared the spatiotemporal variability of temperatures and precipitation with that of the magnitude and timing of maximum daily spring flows in the geographically adjacent L'Assomption River (agricultural) and Matawin River (forested) watersheds during the period from 1932 to 2013. With regard to spatial variability, fall, winter, and spring temperatures as well as total precipitation are higher in the agricultural watershed than in the forested one. The magnitude of maximum daily spring flows is also higher in the first watershed as compared with the second, owing to substantial runoff, given that the amount of snow that gives rise to these flows is not significantly different in the two watersheds. These flows occur early in the season in the agricultural watershed because of the relatively high temperatures. With regard to temporal variability, minimum temperatures increased over time in both watersheds. Maximum temperatures in the fall only increased in the agricultural watershed. The amount of spring rain increased over time in both watersheds, whereas total precipitation increased significantly in the agricultural watershed only. However, the amount of snow decreased in the forested watershed. The magnitude of maximum daily spring flows increased over time in the forested watershed.

\section{Introduction}

Previous work on the hydrological impacts of land use changes (deforestation and agriculture) has revealed that they can vary widely from one region to another depending on numerous factors, such as climate, tree species and type of vegetation, forest management approach, and the physiographic features of watersheds (e.g., [1-3]). There is also controversy around the methods used to determine the effects of deforestation, in particular with regard to flood flows (see [4]).

In Quebec and in other neighbouring provinces in Canada, various studies have looked at the effects of land use changes on flood flows and low flows (e.g., [5-8]). This work has shown that deforestation and/or agriculture have led to an increase in minimum flows. However, they have had virtually no impact on flood flows, particularly spring flood flows from snowmelt. In any event, a number of criticisms can be made regarding these studies.

(i) The studies do not consider variability of temperatures, precipitation, and flows in conjunction with one another. As a result, it is not possible to determine the effects of land use changes on the spatial variability of climate variables (temperature and precipitation), on the one hand, or to accurately distinguish between the effects of land use changes and the effects of climate variability on flows, on the other. Hence, it is not always easy to interpret the hydrological changes that are observed, which can sometimes be attributed incorrectly to the effects of land use changes.

(ii) Most of these studies look solely at the effects of land use changes on the magnitude of floods and low flows. They do not take into account the other elements 
of flows, such as timing, duration, frequency or variability, despite their influence on the functioning of aquatic ecosystems [3].

(iii) These studies do not look at the impact of land use changes on the temporal variability of climate variables or the characteristics of streamflow. They cannot distinguish between the effects of climate variability and those brought about by land use changes in watersheds for which hydrological data from before and after such changes are not available, even though there are many such watersheds in Quebec.

In light of the above, the three goals of this study are as follows:

(1) To compare the spatial and temporal variability of spring peak flood flows in two watersheds that differ in terms of the area of forest cover and the presence of agricultural activity. Spring floods were chosen because previous studies did not highlight the impact of land use changes on maximum daily spring flows. In this study, we look at the impacts on the magnitude and timing of such flows from 1930 to 2013 along with the temporal variability of temperatures and precipitation measured in the two watersheds. The other characteristics (duration, frequency, and variability) of these flows will not be analyzed for the simple reason that they do not vary over time.

(2) To compare the spatial and temporal variability of climate factors (temperature and precipitation) that influence these two characteristics (magnitude and timing) of maximum daily spring flows in the two types of watersheds.

(3) To compare the relationship between these climate factors and the two characteristics of maximum daily spring flows in the two watersheds.

\section{Data and Methodology}

2.1. Choice and Description of Watersheds Analyzed. Two watersheds were selected because of their geographic proximity, the similarity of their physiographic (geographic area, length of watercourse, drainage density, and average slope) and climate properties, and the availability of existing temperature and precipitation data measured over a relatively long period, and their different land use distribution. The first watershed, that of the Matawin River, is fully contained within the Canadian Shield. It is covered entirely by forest and no farming takes place within it. This forested area, which also extends to the L'Assomption River watershed, comprises essentially sugar maple-yellow birch stands [9]. For the Matawin River, the watershed upstream from the Saint-Michel-des-Saints station covers $1390 \mathrm{~km}^{2}$ (Figure 1). Flows have been measured continuously since 1931 and have not been affected by the dam built further downstream in 1930. With regard to the L'Assomption River watershed, two-thirds of it is located within the Canadian Shield and one-third in the Saint Lawrence Lowlands, where intensive agriculture (mostly grains and fodder crops) is practiced. At the Joliette station, the geographic area of the L'Assomption River watershed is $1340 \mathrm{~km}^{2}$. Flows have been measured there on an ongoing basis since 1925. For both watersheds, flow data as well as temperature and precipitation data were taken from the Environment Canada websites [10]. However, unlike for flow data, temperatures and precipitation were measured fairly regularly until 2008 for both watersheds and then only intermittently afterwards.

It is important to note that the magnitude of maximum daily spring flows in the two watersheds, both located on the north shore, is correlated with the Atlantic Multidecadal Oscillation [11], whereas their timing is correlated with the North Atlantic Oscillation [12], and, thus, the two watersheds are affected by the same climate forcing mechanisms.

2.2. Hydroclimatic Series. The following two streamflow series were assembled:

(i) The magnitude of maximum daily spring flows (SMF) series, composed of the highest daily flows measured each spring (from April to June) from 1932 to 2013. Magnitude is expressed in $\mathrm{L} / \mathrm{s} / \mathrm{km}^{2}$ to allow the comparison of magnitude values between the two watersheds, which are dissimilar (albeit very slightly) in size.

(ii) The maximum daily spring flow timing series (STF), comprising the dates on which these flows were measured. Dates are expressed in Julian days.

With regard to climate variables, the following nine series have been assembled:

(i) Three series of mean daily maximum temperatures measured in fall (TMAXf, October to December), winter (TMAXw, January to March), and spring (TMAXs, April to June). Mean values were calculated at the seasonal scale.

(ii) Three series representing mean daily minimum temperatures measured in fall (Tminf, October to December), winter (Tminw, January to March), and spring (Tmins, April to June). Mean values were calculated at the seasonal scale.

We analyzed temperatures for the different seasons because of their influence on the amount of precipitation (snow and/or rain) that in turn affects SMF magnitude and timing. In the fall, temperatures influence the amount of snow. In winter, they affect the amounts of both snow and rain. Finally, in the spring, they affect the amount of snow and the timing of snowmelt. Summer temperatures have no impact on the amount of snow or rain that affects the two SMF characteristics and, for this reason, were not included in this study.

(i) A series representing total snowfall (TSF) from October to May of each year, the time of the year when snowfall and snowmelt occur. However, snowmelt, which produces spring floods, occurs mainly in the spring (April and May). 


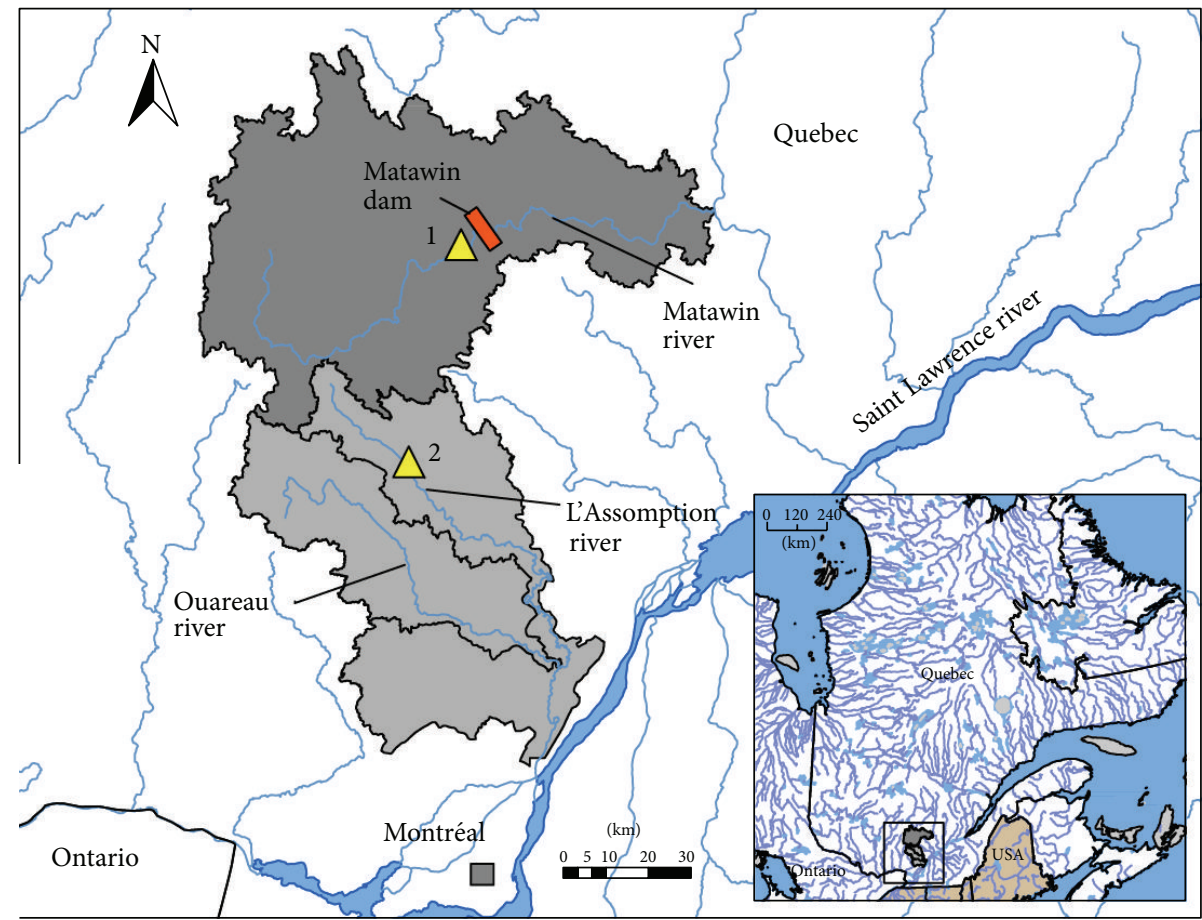

FIGURE 1: Location of two watersheds. 1: Saint-Michel-Des-Saints hydroclimatic station located in Matawin River (forested basin); 2: Joliette hydroclimatic station located in L'Assomption River (agricultural basin).

(ii) A series representing total precipitation (rain and snow) (TP) from October to May of each year.

(iii) Lastly, a series of the total amount of spring rain (STR) measured each year from April to May.

These nine climate variables were selected because they have a direct or indirect impact on spring snowmelt from which spring flood flows arise.

\subsection{Statistical Analysis of Hydroclimatic Series. Statistical} analysis was performed in three steps.

(i) For the first step, we compared the mean values of hydroclimate variable series measured in the two watersheds using Student's $t$-test and the paired $t$ test. The purpose of this step was to compare the spatial variability of hydroclimate variables in order to constrain the effect of differing land uses in the two watersheds. The same results were obtained from both tests.

(ii) For the second step, we looked at the stationarity (changes in arithmetic means) of hydroclimate variables series using the Lombard method [13]. This method can be used to determine the nature and timing of changes (breaks) in mean and variance of a statistical series. The use of this method is justified by its general nature, which makes it possible to detect abrupt or gradual changes, unlike other methods commonly mentioned in the scientific literature (e.g., Pettitt's test). This general nature makes the Lombard method more sensitive than other methods at detecting small breaks in mean or variance. In addition, missing data in a series do not affect the ability to determine the timing of changes in the mean or variance. It is therefore a powerful method [13]. Its mathematical development is presented in detail by [14]. This method was applied after removal of any autocorrelation present in the analyzed series. A change in the mean or variance of a statistical series is considered significant when the $\mathrm{Sn}$ value of the Lombard statistic is higher than the critical theoretical value $(\mathrm{Sn}=0.0403)$ at the $5 \%$ level. The use of this method makes it possible to constrain the effect of differing land uses in the two watersheds on the stationarity (change in mean values) of hydroclimate series.

(iii) For the final step, we correlated the two series of the characteristics (magnitude and timing) of maximum daily spring flows with the nine climate variables series. This correlation was calculated on standardized series in order to eliminate the influence of extreme values on correlation coefficient values. This analysis aims to constrain the effect of differing land uses in the two watersheds on the relationship between the climate variables and the two characteristics of maximum daily spring flows.

\section{Results}

3.1. Comparison of Hydroclimatic Variables in the Two Watersheds to Analyze Their Spatial Variability. Mean values of 
TABLE 1: Comparison of mean values of hydroclimate variables in the L'Assomption River and Matawin River watersheds using Student's $t$-test.

\begin{tabular}{lccc}
\hline Variables & $\begin{array}{c}\text { L'Assomption } \\
\text { River watershed }\end{array}$ & $\begin{array}{c}\text { Matawin River } \\
\text { watershed }\end{array}$ & $p$ values \\
\hline TMaxf $\left({ }^{\circ} \mathrm{C}\right)$ & $4.6(1.50)$ & $2.6(1.46)$ & 0.000 \\
TMaxw $\left({ }^{\circ} \mathrm{C}\right)$ & $-3.1(1.40)$ & $-4.2(1.50)$ & 0.000 \\
TMaxs $\left({ }^{\circ} \mathrm{C}\right)$ & $17.8(1.25)$ & $15.6(1.22)$ & 0.000 \\
$\operatorname{Tminf}\left({ }^{\circ} \mathrm{C}\right)$ & $-4(1.85)$ & $-7(1.74)$ & 0.000 \\
$\operatorname{Tminw}\left({ }^{\circ} \mathrm{C}\right)$ & $-13.4(2.09)$ & $-17.9(2.44)$ & 0.000 \\
$\operatorname{Tmins}\left({ }^{\circ} \mathrm{C}\right)$ & $6.4(0.94)$ & $2.5(1.01)$ & 0.000 \\
$\operatorname{TSF}(\mathrm{cm})$ & $213(76.1)$ & $231(58.3)$ & 0.131 \\
$\mathrm{STR}(\mathrm{mm})$ & $225(75.4)$ & $213(52.4)$ & 0.524 \\
$\operatorname{TP}(\mathrm{mm})$ & $665(139.5)$ & $601(85.8)$ & 0.002 \\
$\mathrm{SMF}\left(\mathrm{L} / \mathrm{s} / \mathrm{km}{ }^{2}\right)$ & $133.6(44.4)$ & $102.7(31.51)$ & 0.000 \\
$\mathrm{STF}(\mathrm{Julian} / \mathrm{Days})$ & $114(10.8)$ & $119(11.7)$ & 0.001 \\
\hline
\end{tabular}

$p$ values $<0.05$ are statistically significant at the $5 \%$ level.

temperature, precipitation, and flow (magnitude and timing) measured in the two watersheds are recorded in Table 1. With regard to temperature, mean maximum and minimum temperatures during the three seasons are higher in the agricultural watershed (L'Assomption) than in the forested one (Matawin). The difference in minimum temperatures is higher than that in maximum temperatures. With regard to precipitation, the total amount of precipitation (rain and snow) is higher in the agricultural watershed than in the forested one. However, the amounts of snow and spring rains do not differ significantly between the two watersheds. With regard to the characteristics of maximum daily spring flows, magnitude is higher in the agricultural watershed than in the forested one. Moreover, this magnitude arises early in the season.

3.2. Comparison of Temporal Variability of Hydroclimate Variables in the Two Watersheds. Results of the analysis of the temporal variability of the hydroclimate variables are presented in Table 2. Maximum and minimum temperatures increased significantly in the fall in the agricultural watershed. Figure 2 shows the temporal variability of mean daily minimum temperature. This increase occurred after 1946 for maximum temperatures and after 1948 for minimum temperatures. In both watersheds, minimum spring temperatures increased significantly in the second half of the 1970s. A similar increase (after 1953) was also observed in winter in the forested watershed alone. The amount of snow decreased significantly in the forested watershed. This decrease occurred after 1976. However, the amount of rain in the spring increased significantly in both watersheds (Figure 3). This increase occurred during the same period, that is, after 1980, in the two watersheds. Lastly, the total amount of precipitation increased significantly in the agricultural watershed after 1992. With regard to flows, means values of the two characteristics (magnitude and timing) changed significantly in the forested watershed (Figures 4 and 5). This change resulted in an increase in the magnitude of maximum

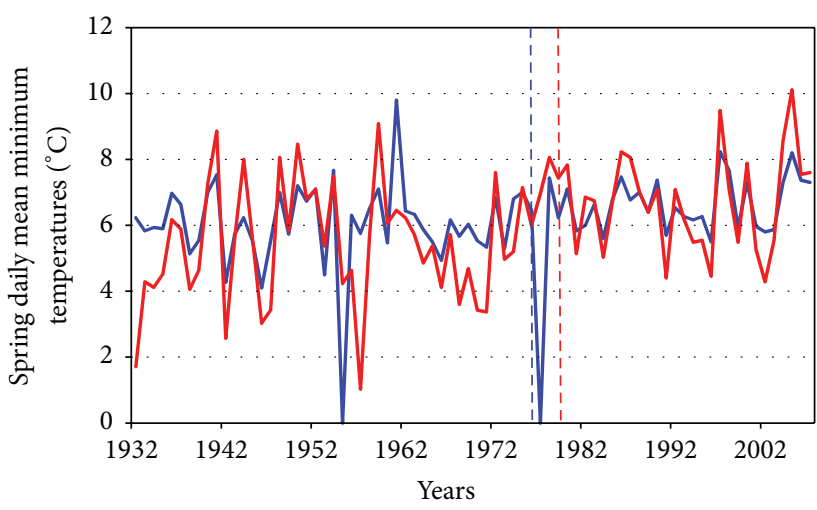

FIgURE 2: Comparison of the temporal variability of mean minimum daily spring temperatures at the Joliette (agricultural watershed, blue curve) and Saint-Michel-des-Saints (forested watershed, red curve) stations. The vertical bar indicates the year in which the significant change in the mean took place.

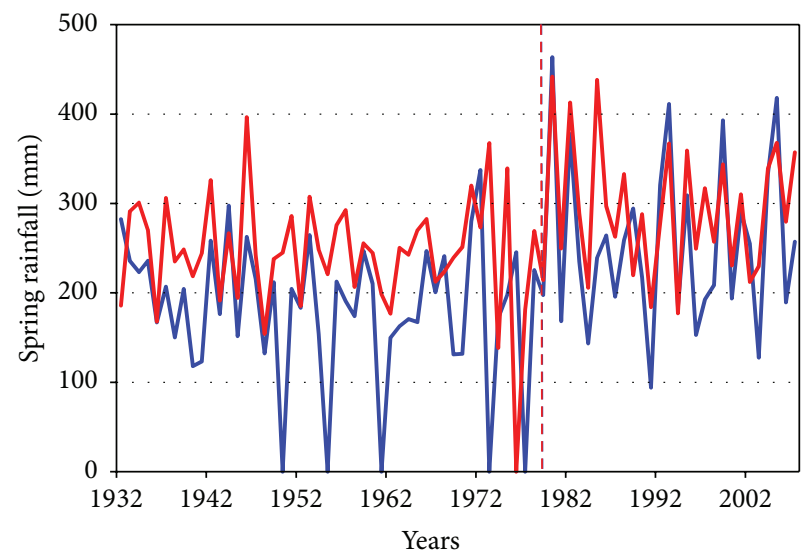

FIgURE 3: Comparison of temporal variability in the amount of spring rain at the Joliette (agricultural watershed, blue curve) and Saint-Michel-des-Saints (forested watershed, red curve) stations. The vertical bar indicates the year in which the significant change in the mean took place. Zero values actually reflect years for which data are missing.

daily spring flows after 1970, and their earlier occurrence after 1987. In contrast, no such changes in the stationarity of these two characteristics are observed in the agricultural watershed.

3.3. Relationship between Climate Variables and the Characteristics of Maximum Daily Spring Flows. Values of coefficients of correlation between hydroclimate variables of the two watersheds are presented in Table 3. With the exception of fall temperatures, there is a fairly strong correlation among the other variables. However, the lowest correlation is between the amounts of snow measured in the two watersheds and the strongest is for the magnitude of maximum daily spring flows. With regard to the link between the two characteristics (magnitude and timing) of streamflow and climate variables (temperature and precipitation), the magnitude of maximum 
TABLE 2: Hydroclimate variables; results of the Lombard method analysis.

\begin{tabular}{|c|c|c|c|c|c|c|}
\hline \multirow{2}{*}{ Variables } & \multicolumn{3}{|c|}{ L'Assomption River watershed } & \multicolumn{3}{|c|}{ Matawin River watershed } \\
\hline & Sn & $\mathrm{T} 1$ & $\mathrm{~T} 2$ & Sn & $\mathrm{T} 1$ & $\mathrm{~T} 2$ \\
\hline$T \operatorname{Maxf}\left({ }^{\circ} \mathrm{C}\right)$ & 0.0434 & 1945 & 1946 & 0.0050 & - & - \\
\hline$T \operatorname{Maxw}\left({ }^{\circ} \mathrm{C}\right)$ & 0.0385 & - & - & 0.0093 & - & - \\
\hline$T \operatorname{Maxs}\left({ }^{\circ} \mathrm{C}\right)$ & 0.0229 & - & - & 0.0121 & - & - \\
\hline $\operatorname{Tminf}\left({ }^{\circ} \mathrm{C}\right)$ & 0.0764 & 1945 & 1948 & 0.0050 & - & - \\
\hline$T \operatorname{minw}\left({ }^{\circ} \mathrm{C}\right)$ & 0.0385 & - & - & 0.0934 & 1952 & 1953 \\
\hline Tmins $\left({ }^{\circ} \mathrm{C}\right)$ & 0.0648 & 1978 & 1979 & 0.0675 & 1975 & 1976 \\
\hline TSF (mm) & 0.0147 & - & - & 0.1182 & 1974 & 1976 \\
\hline $\operatorname{STR}(\mathrm{mm})$ & 0.0550 & 1977 & 1980 & 0.0459 & 1979 & 1980 \\
\hline $\mathrm{TP}(\mathrm{mm})$ & 0.0841 & 1991 & 1992 & 0.0016 & - & - \\
\hline $\operatorname{SMF}\left(\mathrm{L} / \mathrm{s} / \mathrm{km}^{2}\right)$ & 0.0195 & - & - & 0.0553 & 1967 & 1970 \\
\hline $\operatorname{STF}\left(\mathrm{L} / \mathrm{s} / \mathrm{km}^{2}\right)$ & 0.0199 & - & - & 0.0694 & 1986 & 1987 \\
\hline
\end{tabular}

Lombard test $\mathrm{Sn}$ values $>0.0403$ are statistically significant at the $5 \%$ level. T1 and T2 are the years of start and end, respectively, of significant changes in mean and variance values of a given series. f: fall; w: winter; s: spring.

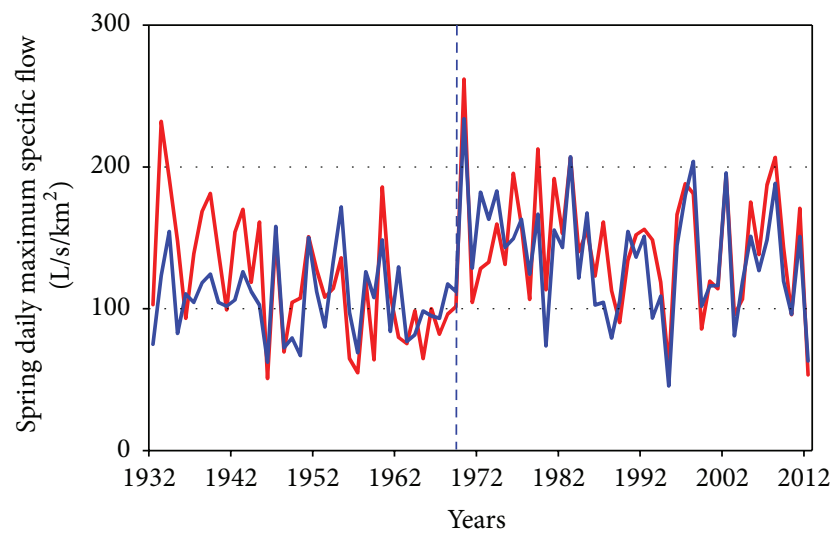

Figure 4: Comparison of temporal variability of the magnitude (specific discharge) of maximum daily spring flows at the Joliette (agricultural watershed, blue curve) and Saint-Michel-des-Saints (forested watershed, red curve) stations. The vertical bar indicates the year in which the significant change in the mean took place.

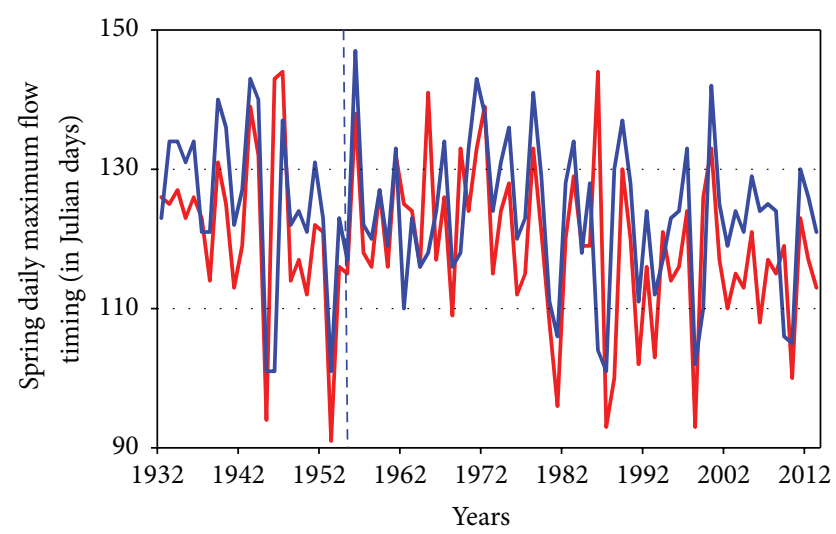

FIGURE 5: Comparison of temporal variability of the timing of maximum daily spring flows at the Joliette (agricultural watershed, blue curve) and Saint-Michel-des-Saints (forested watershed, red curve) stations. The vertical bar indicates the year in which the significant change in the mean took place.
TABLE 3: Correlation coefficients calculated between hydroclimate variables measured in the two watersheds.

\begin{tabular}{lc}
\hline Variables & Coefficients of correlation \\
\hline $\operatorname{TMaxf}\left({ }^{\circ} \mathrm{C}\right)$ & -0.0507 \\
$\operatorname{TMaxw}\left({ }^{\circ} \mathrm{C}\right)$ & $\mathbf{0 . 7 3 2 4}$ \\
$\operatorname{TMaxs}\left({ }^{\circ} \mathrm{C}\right)$ & $\mathbf{0 . 7 7 8 2}$ \\
$\operatorname{Tminf}\left({ }^{\circ} \mathrm{C}\right)$ & 0.0690 \\
$\operatorname{Tminw}\left({ }^{\circ} \mathrm{C}\right)$ & $\mathbf{0 . 6 8 3 6}$ \\
$\operatorname{Tmins}\left({ }^{\circ} \mathrm{C}\right)$ & $\mathbf{0 . 7 6 3 5}$ \\
$\operatorname{TSF}(\mathrm{mm})$ & $\mathbf{0 . 2 8 6 7}$ \\
$\operatorname{STR}(\mathrm{mm})$ & $\mathbf{0 . 6 8 2 6}$ \\
$\operatorname{TP}(\mathrm{mm})$ & $\mathbf{0 . 3 3 1 2}$ \\
$\operatorname{SMF}\left(\mathrm{L} / \mathrm{s} / \mathrm{km}^{2}\right)$ & $\mathbf{0 . 7 5 6 0}$ \\
$\operatorname{STF}\left(\mathrm{L} / \mathrm{s} / \mathrm{km}^{2}\right)$ & $\mathbf{0 . 5 9 1 9}$ \\
\hline
\end{tabular}

Statistically significant coefficient of correlation values at the $5 \%$ level are shown in bold.

daily spring flows is positively correlated with precipitation in both watersheds (Table 4). Timing, for its part, is correlated negatively with winter and spring (maximum and minimum) temperatures in both watersheds. In contrast to precipitation, the correlation between timing and temperature is higher in the agricultural watershed than in the forested one. Table 4 reveals that the two characteristics of streamflow are correlated to the same climate variables. Thus, the difference in land use has no effect on the link between climate variables and the two characteristics of maximum daily spring flows.

\section{Discussion}

Comparison of the spatiotemporal variability of hydroclimate variables for a wholly forested watershed (Matawin River) and an agricultural watershed (L'Assomption River) revealed a number of significant facts. With regard to temperature, mean values of maximum and minimum daily temperatures are systematically higher in the agricultural watershed than in the forested watershed in fall, winter, and spring. The 
TABLE 4: Correlation coefficients calculated between climate variables and characteristics (magnitude and timing) of maximum spring flows (1932-2008).

\begin{tabular}{lcccc}
\hline \multirow{2}{*}{ Climate variables } & \multicolumn{2}{c}{ L'Assomption River watershed } & \multicolumn{2}{c}{ Matawin River watershed } \\
& Magnitude & Timing & Magnitude & 0.0077 \\
TMaxf & -0.1603 & 0.1225 & -0.1119 & $-\mathbf{0 . 2 8 0 5}$ \\
TMaxw & 0.0702 & $-\mathbf{0 . 3 5 6 4}$ & 0.0038 & $-\mathbf{0 . 4 4 8 1}$ \\
TMaxs & -0.0335 & $-\mathbf{0 . 5 1 4 3}$ & -0.0418 & 0.0234 \\
Tminf & -0.1808 & 0.0581 & -0.0993 & $-\mathbf{0 . 2 4 3 6}$ \\
Tminw & 0.0195 & $-\mathbf{0 . 3 3 8 7}$ & -0.0212 & $-\mathbf{0 . 5 0 5 0}$ \\
Tmins & 0.0884 & $-\mathbf{0 . 4 5 7 5}$ & 0.0921 & 0.1859 \\
TSF & $\mathbf{0 . 2 4 3 9}$ & 0.1913 & $\mathbf{0 . 4 1 5 0}$ & 0.0038 \\
STR & $\mathbf{0 . 2 3 6 8}$ & -0.0404 & $\mathbf{0 . 3 0 1 9}$ & -0.0103 \\
TP & $\mathbf{0 . 3 0 0 2}$ & -0.0021 & $\mathbf{0 . 5 0 0 8}$ \\
\hline
\end{tabular}

Statistically significant coefficient of correlation values at the $5 \%$ level are shown in bold.

difference between the two watersheds is greater for minimum temperatures than for maximum temperatures. This temperature difference may be partly explained by the "shading" effect of forest cover, which reduces the amount of solar energy that reaches the ground surface. In addition, a portion of the solar energy is used by trees for evapotranspiration. With regard to precipitation, the two watersheds differ mainly in the total amount of precipitation, which is higher in the agricultural watershed than in the forested watershed. Given that the amount of snow and the amount of spring rainfall are not significantly different in the two watersheds, this increase in total precipitation in the agricultural watershed is apparently due to the increase in total rainfall during the fall given, since the amount of rain in winter is not significantly different in the two watersheds either. This means that the difference in land use does not affect the spatial variability of the amounts of snow and rain in winter and spring. It is in the fall that climate differences between the two watersheds are evident. This explains the lack of correlation observed between climate variables measured in the two watersheds.

With regard to the characteristics of flows, the magnitude of maximum daily flows was found to be higher in the agricultural watershed than in the forested watershed, despite a significant increase in magnitude over time (Table 2) in the latter watershed. All of the previous work carried out in Quebec has shown that land use has very little impact on flood flows in general, and on spring flood flows in particular $[6,7]$. A number of different factors may account for the magnitude of maximum daily spring flows being higher in the agricultural watershed than in the forested watershed.

(1) In the agricultural watershed, the total amount of precipitation measured from October to April is higher than in the forested watershed. This could cause spring flood flows to be higher in the first watershed than in the second. However, spring flood flows are generated mainly by snowmelt, sometimes in conjunction with spring rains. It has been established that there is no significant difference between the amounts of snow and rain in the two watersheds, with the exception of fall rain, which has no bearing whatsoever on spring floods.
(2) Drainage density and the relatively high slope of the agricultural watershed could account for higher peak flows in the spring. However, these two factors do not come into play, as they are very similar in the two watersheds. In addition, in the agricultural watershed, slopes, and drainage density are much lower in the area in which agricultural land is concentrated.

(3) Because of the decrease in forest cover (decrease in interception of precipitation) and because of farming activities, runoff is becoming more important in the agricultural watershed than in the forested watershed. Despite low slopes, the decrease in the infiltration capacity of the soil as a result of mechanized agriculture appears to result in much more substantial runoff, which in turn would account for higher peak floods. This phenomenon has been extensively documented in many parts of the world [3].

(4) A significant decrease in total snowfall over time was observed in the forested watershed. However, as this decrease is incompatible with the increase in the magnitude of maximum daily spring flows, it is excluded as a possible explanation for the difference in magnitude between the two watersheds.

With regard to the timing of maximum daily spring flows, they occur earlier in the season in the agricultural watershed than in the forested watershed, despite the change over time in their mean values in the latter watershed. This relatively early onset could be explained by higher maximum and minimum spring temperatures in the first watershed as compared with the second.

Analysis of the temporal variability of temperatures using the Lombard method revealed that mean daily maximum temperatures in the agricultural watershed increased significantly over time in the fall. This increase, which did not occur in the forested watershed, took place during the second half of the 1940s. However, there is no reason to link this increase with the decrease in forest cover or the development of intensive agriculture that began after this decade. With regard to minimum temperatures, they increased significantly over time in spring in both watersheds, 
in fall in the agricultural watershed and in winter in the forested watershed. This increase cannot be linked to the difference in land use. Rather, it reflects the changes that affect the temporal variability of temperatures throughout Quebec. Similar increases have been observed in numerous watersheds in Quebec. Minimum temperatures are more strongly affected than maximum temperatures $[15,16]$. With regard to precipitation, the amount of spring rain increased significantly over time in the two watersheds after 1980, while the amount of precipitation did not increase in the agricultural watershed until after 1992. However, the amount of snow decreased significantly in the forested watershed after 1976. Such changes in precipitation have also been observed in other watersheds in Quebec. They therefore cannot be linked to land use changes. With regard to the amount of snow in particular, [17] has observed a significant decrease in snowpack since the 1980s in Quebec. According to [16], this decrease has had a particularly notable impact on the north shore of the St. Lawrence River (where the two watersheds are located), which is characterized by a continental-type climate.

The magnitude of maximum daily spring flows increased significantly over time in the forested watershed only after 1970. This increase could be linked to the increase in the amount of spring rain, since the amount of snow decreased significantly over time in the watershed. However, the changes in mean values of these variables are not synchronous. Thus, the increase in flow magnitude occurred approximately 10 years before the increase in the amount of spring rain. It seems that flows are much more sensitive to gradual changes in the amount of rain. The absence of change in magnitude of maximum daily spring flows in the agricultural watershed could partly be explained by a fairly high evaporation owing to relatively high temperatures that could mitigate the effects of the increase in spring rains. With regard to the timing of maximum daily spring flows, its temporal variability is reflected in their earlier timing in the forested watershed, likely because of the increase in minimum temperature in winter and spring. However, despite an increase in minimum temperature in spring, no change in the timing of these flows was observed in the agricultural watershed.

Analysis of the correlation between hydroclimate variables for the two watersheds revealed a strong link between these variables, with the exception of fall temperatures, which appear to be influenced by site-specific conditions. The correlation for total snowfall is very weak, albeit significant. The weakness of this correlation shows that the amount of snow is partly influenced by site conditions, particularly in the fall. Analysis of the relationship between climate variables and the two characteristics of streamflow in the two watersheds revealed that magnitude is positively correlated with precipitation (snow and rain). This correlation is higher in the forested watershed than in the agricultural watershed, probably because of the influence of relatively high temperatures, which promotes evapotranspiration and therefore affects the connection between precipitation and flow. With regard to the timing of maximum daily spring flows, it is negatively correlated with maximum and minimum winter and spring temperatures in both watersheds. When temperatures are high, snowmelt giving rise to spring floods occurs early in the season. This correlation is higher in agricultural watershed than in the forested one due to the fact that temperatures are higher in the former than in the latter.

\section{Conclusion}

This study brought out the respective effects of land use on the spatiotemporal variability of temperature, precipitation, and streamflow characteristics in Quebec. As far as spatial variability is concerned, the difference in land use results in higher maximum and minimum seasonal temperatures and maximum daily spring flow magnitude in the agricultural watershed than in the forested watershed. As for the timing of maximum daily spring flows, they occur earlier in the agricultural watershed than in the forested watershed. With regard to the temporal variability of these hydroclimate variables, breaks in mean values that affect some of these variables occurred essentially at the same time as those observed in other watersheds in Quebec. Therefore, they cannot be linked to the difference in land use between the two watersheds. Finally, the difference in land use between the two watersheds has no effect on the link between climate variables (temperature and precipitation) and the two characteristics (magnitude and timing) of maximum daily spring flows. In both watersheds, flow magnitude is positively correlated with winter and spring temperatures, while timing is negatively correlated with these variables.

\section{Conflict of Interests}

The authors declare that there is no conflict of interests regarding the publication of this paper.

\section{References}

[1] V. Andréassian, "Waters and forests: from historical controversy to scientific debate," Journal of Hydrology, vol. 291, no. 1-2, pp. 127,2004

[2] C. Cosandey, V. Andréassian, C. Martin et al., “The hydrological impact of the mediterranean forest: a review of French research," Journal of Hydrology, vol. 301, no. 1-4, pp. 235-249, 2005.

[3] N. L. Poff, B. P. Bledsoe, and C. O. Cuhaciyan, "Hydrologic variation with land use across the contiguous United States: geomorphic and ecological consequences for stream ecosystems," Geomorphology, vol. 79, no. 3-4, pp. 264-285, 2006.

[4] Y. Alila, P. K. Kuraś, M. Schnorbus, and R. Hudson, "Forests and floods: a new paradigm sheds light on age-old controversies," Water Resources Research, vol. 45, no. 8, 2009.

[5] D. Caissie, S. Jolicoeur, M. Bouchard, and E. Poncet, "Comparison of streamflow between pre and post timber harvesting in Catamaran Brook (Canada)," Journal of Hydrology, vol. 258, no. 1-4, pp. 232-248, 2002.

[6] M. Lavigne, A. N. Rousseau, R. Turcotte, A.-M. Laroche, J.-P. Fortin, and J.-P. Villeneuve, "Validation and use of a semidistributed hydrological modelling system to predict short-term effects of clear-cutting on a watershed hydrological regime," Earth Interactions, vol. 8, no. 3, pp. 1-19, 2004. 
[7] M. Muma, A. A. Assani, R. Landry, J. Quessy, and M. Mesfioui, "Effects of the change from forest to agriculture land use on the spatial variability of summer extreme daily flow characteristics in southern Quebec (Canada)," Journal of Hydrology, vol. 407, pp. 153-163, 2011.

[8] R. Quilbé, A. N. Rousseau, J. Moquet, S. Savary, S. Ricard, and M. S. Garbouj, "Hydrological responses of a watershed to historical land use evolution and future land use scenarios under climate change conditions," Hydrology and Earth System Sciences, vol. 12, no. 1, pp. 101-110, 2008.

[9] C. Fortier, A. A. Assani, M. Mesfioui, and A. G. Roy, "Comparison of the interannual and interdecadal variability of heavy flood characteristics upstream and downstream from dams in inversed hydrologic regime: case study of Matawin River (Québec, Canada)," River Research and Applications, vol. 27, no. 10, pp. 1277-1289, 2011.

[10] Environment Canada Web Page, Données Hydrométriques, 2014, http://climat.meteo.gc.ca/advanceSearch/searchHistoricData_f.html?

[11] A. A. Assani, S. Charron, M. Matteau, M. Mesfioui, and J.-F. Quessy, "Temporal variability modes of floods for catchments in the St. Lawrence watershed (Quebec, Canada)," Journal of Hydrology, vol. 385, no. 1-4, pp. 292-299, 2010.

[12] R. Mazouz, A. A. Assani, J. Quessy, and G. Légaré, “Comparison of the interannual variability of spring heavy floods characteristics of tributaries of the St. Lawrence River in Quebec (Canada)," Advances in Water Resources, vol. 35, pp. 110-120, 2012.

[13] F. Lombard, "Rank tests for changepoint problems," Biometrika, vol. 74, no. 3, pp. 615-624, 1987.

[14] J.-F. Quessy, A.-C. Favre, M. Saïd, and M. Champagne, "Statistical inference in Lombard's smooth-change model," Environmetrics, vol. 22, no. 7, pp. 882-893, 2011.

[15] A. Yagouti, G. Boulet, L. Vincent, L. Vescovi, and É. Mekis, "Observed changes in daily temperature and precipitation indices for southern Québec, 1960-2005," Atmosphere-Ocean, vol. 46, no. 2, pp. 243-256, 2008.

[16] N. Guerfi, A. A. Assani, M. Mesfioui, and C. Kinnard, "Comparison of the temporal variability of winter daily extreme temperatures and precipitations in southern Quebec (Canada) using the Lombard and copula methods," International Journal of Climatology, 2015.

[17] R. D. Brown, "Analysis of snow cover variability and change in Québec, 1948-2005," Hydrological Processes, vol. 28, pp. 40114022, 2010. 

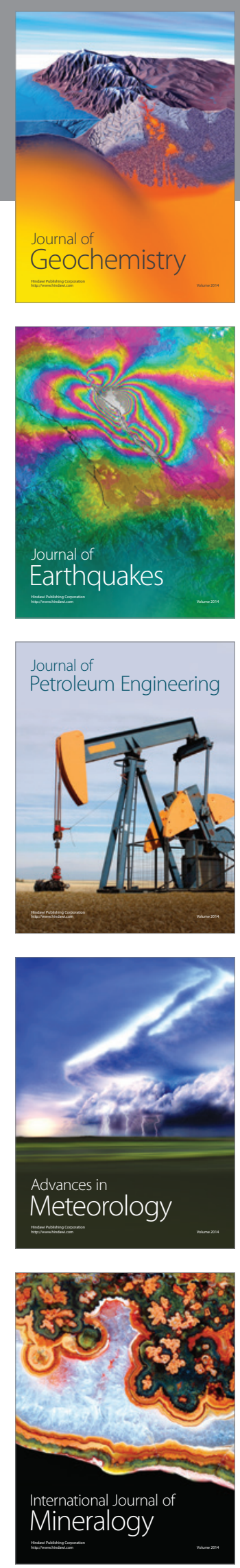
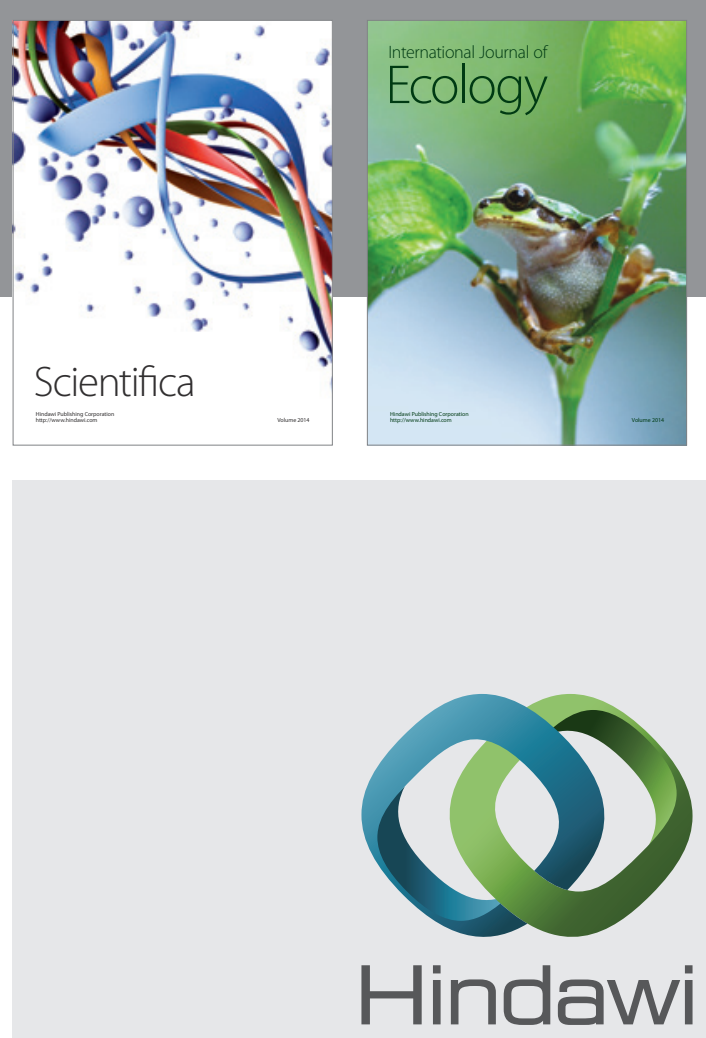

Submit your manuscripts at

http://www.hindawi.com
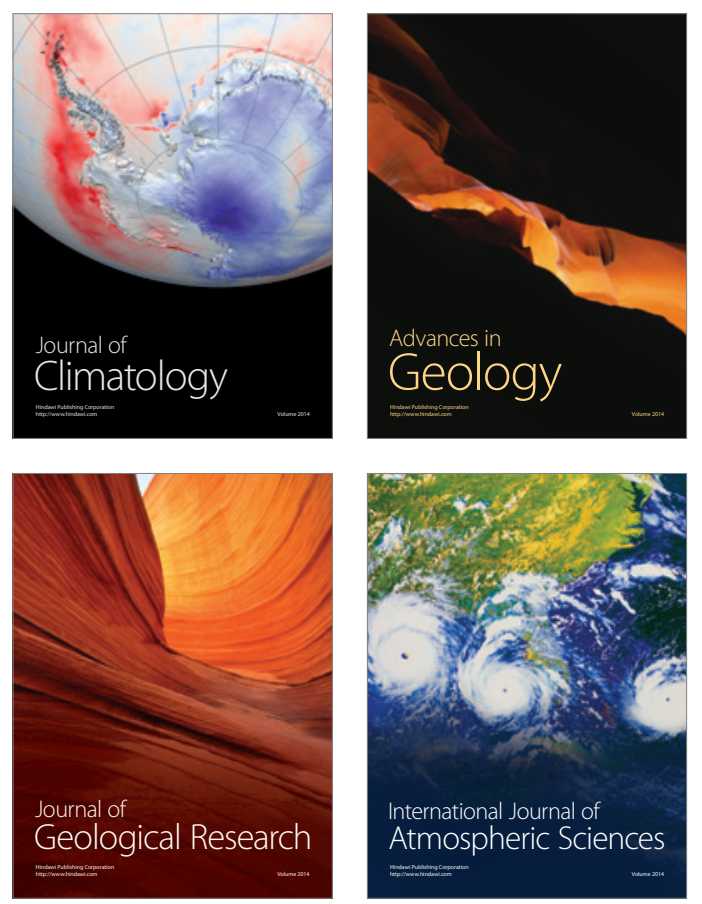

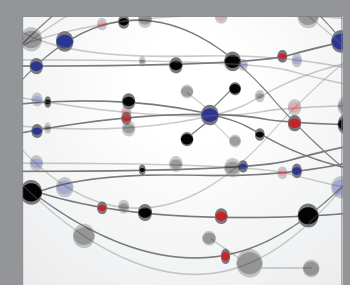

The Scientific

\section{World Journal}
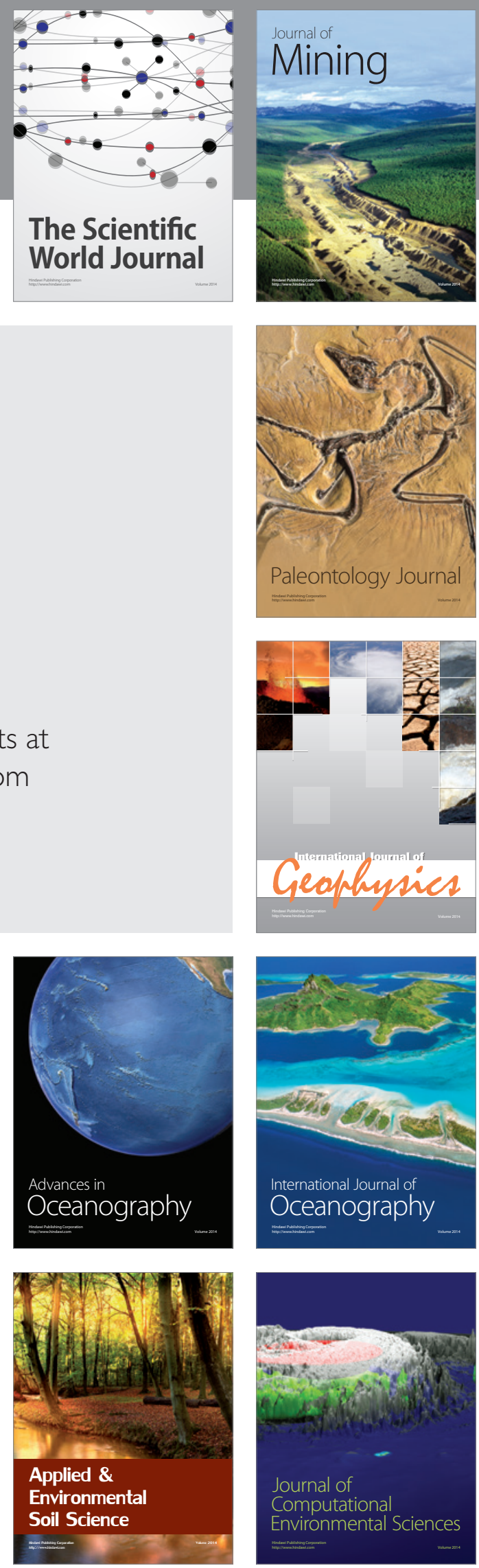